\title{
Análise da organização do ensino da matemática na educação infantil sob o olhar da teoria histórico-cultural ${ }^{1}$
}

\section{Marlova Neumann Araujo}

Professora da rede Estadual de Ensino de Santa Catarina

Universidade do Extremo Sul Catarinense - UNESC

marlova05@hotmail.com

\section{Ademir Damazio}

Universidade do Extremo Sul Catarinense - UNESC

add@unesc.net

\begin{abstract}
Resumo
O presente artigo apresenta a análise da organização do ensino da Matemática de uma Proposta Curricular de Educação Infantil de um município do sul do Santa Catarina, que indica a Teoria Histórico-Cultural como seu fundamento. Utilizaram-se os princípios do método de Vigotski para a análise do objeto de estudo: as orientações para a organização do ensino de matemática na Educação Infantil, em instância municipal. Verificou-se divergência entre a prática de organização proposta com a teoria aclamada, que se manifesta em indicações fossilizadas, pois expressa pensamentos correntes nos âmbitos escolares sem respaldo teórico, bem como pela evidência de entendimento, expresso no documento, de tendências e modelos organizacionais construtivistas.
\end{abstract}

Palavras-chave: Educação Infantil. Histórico-Cultural. Organização do Ensino. Currículo. Matemática.

\section{Analysis of the organization of mathematics teaching in children education on the look at the historical-cultural theory}

\begin{abstract}
This article introduce the analysis of the organization of the teaching of Mathematics of a Curricular Proposal of Early Childhood Education of a municipality in the south of Santa Catarina, for indicating the Historical-Cultural Theory as foundation. The principles of the Vygotsky method were used to analyze the object of study: the guidelines for the organization of mathematics teaching in Early Childhood Education, in a municipal instance. There was a divergence between the proposed organization practice with the acclaimed theory that manifests itself in: calcify indications, because it expresses current thoughts in the school environments without theoretical
\end{abstract}

\footnotetext{
${ }^{1}$ Artigo elaborado com base na dissertação de mestrado da primeira autora que foi orientada pelo segundo autor.
} 
support; As well as the evidence of understanding, expressed in the document, of trends and constructivist organizational models.

Keywords: Early Childhood Education. Historical-Cultural. Organization of Teaching. Curriculum. Mathematics.

\section{Introdução}

A referência, no presente estudo, é o ensino da Matemática na Educação Infantil. Adota como marco a atualização das Diretrizes Curriculares Nacionais Educação Básica (BRASIL, DCNEB, 2013).-Outra referência é a Proposta Curricular do Estado de Santa Catarina que orienta a organização pedagógica da Educação Infantil e traz prenúncios da Teoria do Ensino Desenvolvimental. É no âmbito das mencionadas orientações - uma em nível nacional e a outra estadual - que se apresenta o objeto de estudo: a organização do ensino de matemática no processo na Educação Infantil, em instância municipal. A questão básica centra-se nas orientações das Diretrizes para a Educação Infantil de uma rede municipal - que se apresenta como fundamentada na Teoria Histórico-Cultural - referente ao ensino de matemática. Para tanto, levaram-se em consideração os pressupostos da referida teoria, articuladamente com os princípios pertinentes à organização de ensino.

\section{Metodologia}

Para o desenvolvimento do estudo, a base metodológica é os três princípios do método de Vigotski (2001). O primeiro deles - análise do processo e não do objeto - requereu uma exposição dinâmica dos principais pontos constituintes do movimento gerador das indicações teórico/metodológicas da Proposta Curricular Municipal de Educação Infantil, fonte das análises. O segundo - explicação versus descrição - focou em aspectos distintos priorizados por diferentes correntes explicativas, a fim de evitar o relato descritivo que, segundo Vigotski (2001), percebe apenas as manifestações e a aparência. Por isso, a análise objetiva centrou-se nas orientações curriculares para o ensino de matemática voltado às crianças em idade pré-escolar, com atenção para as ligações reais entre os conceitos elencados e os princípios metodológicos para o seu desenvolvimento em sala de aula.

Nesse sentido, foi essencial a inserção nos pressupostos e conceitos da Teoria do HistóricoCultural e do Ensino Desenvolvimental, uma vez que esse é o referencial explicitado pela Proposta do Município. Isso significa que houve a preocupação em atender as orientações de Vigotski (2001) 
para que se rejeite as descrições nominais - por exemplo, somente elencar os conceitos matemáticos e identificar as respectivas indicações metodológicas - a fim de focar-se nas determinações das relações dinâmico-causais do objeto.

Sendo assim, admitiu-se como importante a explicação científica do processo das manifestações externas do objeto de estudo e das idiossincrasias fenotípicas para subordiná-las à descoberta de sua origem e desenvolvimento. Isso leva à atenção ao terceiro princípio - o problema do comportamento fossilizado - que, no caso do presente estudo, trata-se de expressões automatizadas ou mecanizadas no senso comum escolar, repetidas no documento analisado, pois, conforme Vigotski (2001), esse tipo de conduta esconde a aparência original e revela apenas aspectos externos.

Vale salientar que a base de análise é o documento produzido no âmbito da Secretaria de Educação de um município - localizado no sul do Estado de Santa Catarina - com intuito de orientar a organização do ensino da Matemática da Educação Infantil. O documento intitula-se “Proposta Curricular da Rede Municipal de Ensino de (X) - Educação Infantil”. Para evitar a exposição do município, foi nomeado por X, e adotada a abreviatura PCEIMX (Proposta Curricular de Educação Infantil do Município X). O critério primordial para adotá-la como base de análise foi sua indicação de que se fundamenta na Teoria Histórico-Cultural.

O objeto e o problema da pesquisa, bem como o seu referencial teórico colocam como essencial na análise os princípios e orientações de organização do ensino de matemática na Educação Infantil, concebidos a partir da Teoria Histórico-Cultural.

\section{Ensino da Matemática na Educação Infantil: pressupostos da Teoria Histórico- Cultural}

Na teoria histórico-cultural, o ensino da matemática, desde a educação infantil, deve partir de uma dimensão histórico-lógica, o que significa perceber o movimento histórico-cultural do homem, ao transformar a natureza em busca de melhores condições de vida- (ARAÚJO, 2010). Segundo Moura e Lanner de Moura (2007), ao longo dos tempos, a matemática e o conhecimento matemático apresentaram um desenvolvimento a partir da necessidade do homem de controlar, de medir e de contar. Para isso, utilizaram sistemas de signos, que foram compartilhados com todos os membros de um grupo, em ações colaborativas.

Para Davídov (1988), o ensino e a educação alcançam suas finalidades se a atividade própria da criança está devidamente orientada. Quando esta atividade é interpretada abstratamente e, principalmente, quando existe uma ruptura do processo de desenvolvimento em relação à 
educação e ao ensino, inevitavelmente surgirá algum tipo de pedocentrismo ou de contraposição entre as necessidades da "natureza" da criança e os requisitos da educação. Segundo o autor, a situação muda se a atividade "própria" da criança for entendida, de um lado, como algo que surge e se forma no processo de educação e ensino e, de outro, se for vista no contexto da história da própria infância, determinada pelas tarefas socioeconômicas da sociedade e pelas finalidades e possibilidades de educação e ensino que a elas correspondem. Dadas estas premissas teóricas, o fato de considerar a natureza e os aspectos específicos da atividade infantil não leva à contraposição entre o desenvolvimento e a educação, mas sim à introdução de uma condição fundamental para a concretização das finalidades pedagógicas.

De acordo com Moura e Lanner de Moura (2007), o ensino no período pré-escolar tem como objetivo principal a compreensão, pela criança, do mundo simbólico que a cerca e, mais do que isso, possa de fato tornar sua, a experiência social da humanidade. No caso da matemática, significa que a organização do ensino, na dimensão do que ensinar e do como ensinar, deve considerar o movimento histórico-cultural do homem ao desenvolver esse conhecimento, em busca de melhores condições de vida. Isto ultrapassa a visão da necessidade de conhecimentos prévios, bem como o caráter utilitarista da matemática.

Para Leontiev (1978), as conquistas diárias individuais resultam processos compartilhados, no qual cada indivíduo, desde seu nascimento, se apropria de conhecimento a partir da relação com o outro ou com o meio, ou seja, ele transforma e é transformado nas relações produzidas na cultura em que se insere por meio de um processo de interiorização e atribuição de significados próprios às situações de que participa. Segundo o autor, esse processo se caracteriza como atividade, que se constitui em unidade de formação do sujeito na qual as necessidades emocionais e materiais dirigem as suas ações. Uma atividade compreende: o objeto, o motivo, a ação, a operação, a consciência do fim e do objetivo.

É nessa perspectiva que Leontiev (1978) declara que a criança tem o contato com a matemática desde o nascimento, pois interage com grandezas diversas e objetos, produções humanas materiais ou ideais. Porém, somente nos espaços escolares que ela se depara com outro modo de aprender. O desenvolvimento humano é caracterizado por etapas marcadas por uma determinada atividade que Leontiev (1978) denomina de atividade principal. São elas, o jogo, no período pré-escolar; estudo, na idade escolar; e o trabalho, marcadamente na idade adulta. Portanto, em situação de Educação Infantil - do sistema escolar brasileiro - a criança tem o jogo como atividade principal, isto é, um modo de ocupar um lugar na sociedade humana (LEONTIEV, 1978).

Araújo (2010) entende que, na Educação Infantil, se inicia o processo de apropriação de conhecimentos sistematicamente produzidos pela humanidade. Sendo assim, o papel do professor, 
em sua atividade de ensino, é proporcionar as interações com os estudantes mediadas pelo conhecimento, isto é, estabelecer ações que oportunizem a aprendizagem. A criança só se apropria do conhecimento matemático historicamente acumulado com a intervenção de alguém que tenha o domínio conceitual. A atividade educativa, na perspectiva da teoria Histórico-cultural, não trata apenas da mera transmissão de conhecimentos, mas aquele que possibilita ao indivíduo singular, no caso a criança, a se apropriar da experiência social humana.

Moura e Lanner de Moura (2007) asseveram que, na educação infantil, a atividade que permite colocar a criança em situação de apropriação de um conhecimento matemático é Atividade Orientadora de Ensino (AOE). Esta tem como referência uma situação desencadeadora da aprendizagem, que possibilite o compartilhamento de significados na solução de problemas. Segundo Moura (2010, p. 97), "na AOE, ambos, professor e estudante, são sujeitos em atividade e como sujeitos se constituem indivíduos portadores de conhecimentos, valores e afetividade, que estarão presentes no modo como realizarão as ações que têm por objetivo um conhecimento de qualidade nova." Para o autor, uma atividade só pode ser orientadora de ensino e de aprendizagem se os sujeitos, ao agirem em um espaço de aprendizagem, modificam-se e constituem-se com outra qualidade.

Para Moura (2013, p. 320), “o que distingue uma atividade de outra é o seu objeto e o seu motivo, e estes devem coincidir dentro da atividade". Um sujeito se encontra em atividade quando o objetivo de sua ação coincide com o motivo de sua atividade, para satisfazer uma necessidade individual e do grupo em relação com o mundo, a fim de atingir um objetivo.

De acordo com Moura et al (2010), o ensino tomado como atividade, com caráter de processo social - mediado por instrumentos e signos e estruturado com base em uma necessidade exige um modo especial de organização. A qualidade da atividade de ensino se apresenta quando ele propicia o surgimento da necessidade de proporcionar a apropriação da cultura. É a partir do modo de organização de ensino que se articulam entre si os objetivos, as ações e as operações da atividade pedagógica (ensino e aprendizagem), que permite à AOE uma dimensão de unidade formadora do estudante e do professor, para a concretização da apropriação da cultura e dos conceitos científicos. Por consequência, contribui para que as crianças desenvolvam o pensamento teórico e as funções psíquicas: memória lógica, atenção voluntária, pensamento, linguagem (VIGOTSKI, 2001).

$\mathrm{Na}$ AOE, as necessidades, os motivos, os objetivos, as ações e as operações do professor e dos estudantes se mobilizam, inicialmente, por meio da 'situação desencadeadora de aprendizagem', que tem como objetivo proporcionar a necessidade da apropriação do conceito pelo estudante. Ela deve contemplar a gênese do conceito, isto é, a sua essência; além disso, explicitar a 
necessidade que levou a humanidade à construção do referido conceito. Coloca em destaque os problemas e as necessidades humanas em determinada atividade, bem como as soluções ou sínteses produzidas no seu movimento lógico-histórico.

As situações desencadeadoras de aprendizagem podem ser materializadas por meio de diferentes recursos metodológicos, como: o jogo, as situações emergentes do cotidiano e a história virtual (MOURA et al, 2010). Nesse sentido, Grando (2000) diz que o jogo, com suas regras, pode estabelecer um caminho natural que vai da imaginação à abstração de um conceito matemático. $\mathrm{O}$ jogo, como situação desencadeadora de aprendizagem, não se caracteriza apenas pelo seu teor lúdico por possibilitar que as crianças interajam com objetos ou reproduzam a relação dos adultos com eles, mas, sobretudo, por propor situações nas quais estejam latentes as relações das pessoas entre si mediadas por um conceito matemático teórico.

Segundo Moura e Lanner de Moura (1998), a história virtual - como situação desencadeadora para o ensino da matemática da Educação Infantil - é uma forte aliada para que surja, na criança, a necessidade de compartilhar saberes com colegas e professores, além de apropriá-los como um saber individual.

A resolução de um problema - que tem por base uma lenda, mito ou outra história qualquer - pela criança propicia-lhe a atribuição de significados e sentidos ao conceito matemático em foco, dado que sua resolução ocorre de forma compartilhada e negociada no grupo. Na situação de jogo de papéis e na história virtual, é possível explorar ainda situações do cotidiano, que também desencadeia a aprendizagem.

Davydov (1999), em sua proposição de organização do ensino de Matemática, atenta para estrutura da atividade teorizada por Leontiev, qual seja: necessidade, o motivo, a finalidade, as condições para obter a finalidade. Estes componentes se relacionam com outros correlatos que são a atividade, a ação e a operação. O autor inclui o desejo como núcleo básico de uma necessidade, por considerar que ambos compõem a base sobre as quais funcionam as emoções.

No início do processo escolar, a responsabilidade é com a formação das características que envolvem a necessidade de estudar e a capacidade de aprender. Por isso, Davídov (1982) adverte que, nos primeiros meses de ensino, é muito perigoso exigir dos alunos a simples memorização de determinados conhecimentos sem que, para isso, eles tenham a devida compreensão dos mesmos. A prática de ensino assim organizada consegue um efeito direto do estudo, mas não tem como formar nos estudantes o interesse cognoscitivo para o material didático, o que implica de forma negativa em todo o trabalho escolar anterior. 
Por decorrência, urge que o professor da educação infantil compreenda os conceitos científicos, tanto específicos da matemática, quanto aos referentes ao desenvolvimento humano. Também, tenha uma concepção de ensino como um processo intencional gerador, nas crianças, da necessidade e do motivo para aprender- (ARAÚJO, 2015).

\section{Princípios Histórico-Cultural para a organização dos conceitos Matemáticos na Educação Infantil}

A PCEIMX explicita a concepção de matemática como "linguagem matemática" e, ao mesmo tempo, alerta para o contato que tem a criança com a matemática, desde cedo. Alerta que o conhecimento matemático ultrapassa a ideia de contar, repartir, somar ou diminuir:

A criança entra em contato com a linguagem matemática desde cedo. Questões bastante rotineiras acabam por proporcionar situações em que os conhecimentos matemáticos são necessários e, assim, o cotidiano oferece inúmeras oportunidades que vão muito além do recitar números na ordem correta: contar figurinhas, conferir os pontos durante um jogo, repartir o material com outras crianças, comparar as idades, observar o número de casa ou dos telefones dos amigos, etc. (PCEIMX, 2012, p. 47).

O documento, ao tratar o conhecimento matemático como linguagem, não dá explicação desse entendimento, o que se torna um chavão do senso comum, um comportamento fossilizado corrente nos meios escolares. No entanto, Vigotski (2001, p. 111) diz:

A relação entre pensamento e linguagem modifica-se no processo de desenvolvimento tanto no sentido quantitativo quanto qualitativo. Noutros termos, o desenvolvimento da linguagem e do pensamento realiza-se de forma não paralela e desigual. As curvas desse desenvolvimento convergem e divergem constantemente, cruzam-se, nivelam-se em determinados períodos e seguem paralelamente, chegam a confluir em algumas de suas partes para depois bifurcarse.

Há, pois, uma unidade entre o pensamento e a linguagem, cujas modificações específicas, quantitativas e qualitativas, se influenciam no processo de desenvolvimento. Segundo Vigotski (2001), a criança utiliza a linguagem com função comunicativa; depois, gradualmente, a linguagem oral assume função psíquica ao ser utilizada como instrumento da capacidade de pensar e, posteriormente, se interioriza e se constitui em fala interior.

Entender a Matemática como linguagem na educação infantil é de grande relevância, uma vez que ela é aquilo pelo qual se generaliza e se transmite a experiência da prática sócio histórica da humanidade. É um meio de comunicação, condição da apropriação dos indivíduos das experiências e a forma da sua existência na consciência.

Como linguagem, há no conhecimento matemático a manifestação de elementos culturais e de ferramentas simbólicas criadas pelos homens. Para Moraes (2010, p. 2), a teoria histórico- 
cultural diz que apropriar "dos conhecimentos matemáticos constitui-se em uma das formas dos sujeitos tornarem-se sujeitos da cultura". Nas instituições de Educação Infantil, é essencial que ocorra a organização das interações entre adulto, criança e conhecimento.

Por isso, a apropriação desse conteúdo cultural é condição para a vivência em seu grupo e resolver as situações que surgem, a fim de entender seu entorno. Ela salienta que a criança, desde muito cedo, tem a percepção numérica que também pode ser chamada de "senso numérico". A autora destaca ainda que a criança vive em uma sociedade numeralizada que utiliza a forma mais elaborada de controle de quantidade, antes mesmo que compreenda o cálculo.

A Proposta do município elenca os conceitos matemáticos a serem elaborados pelas crianças, em conformidade com a idade, conforme apresenta o Quadro 1.

Quadro 1 - Relação dos conceitos matemáticos por idade.

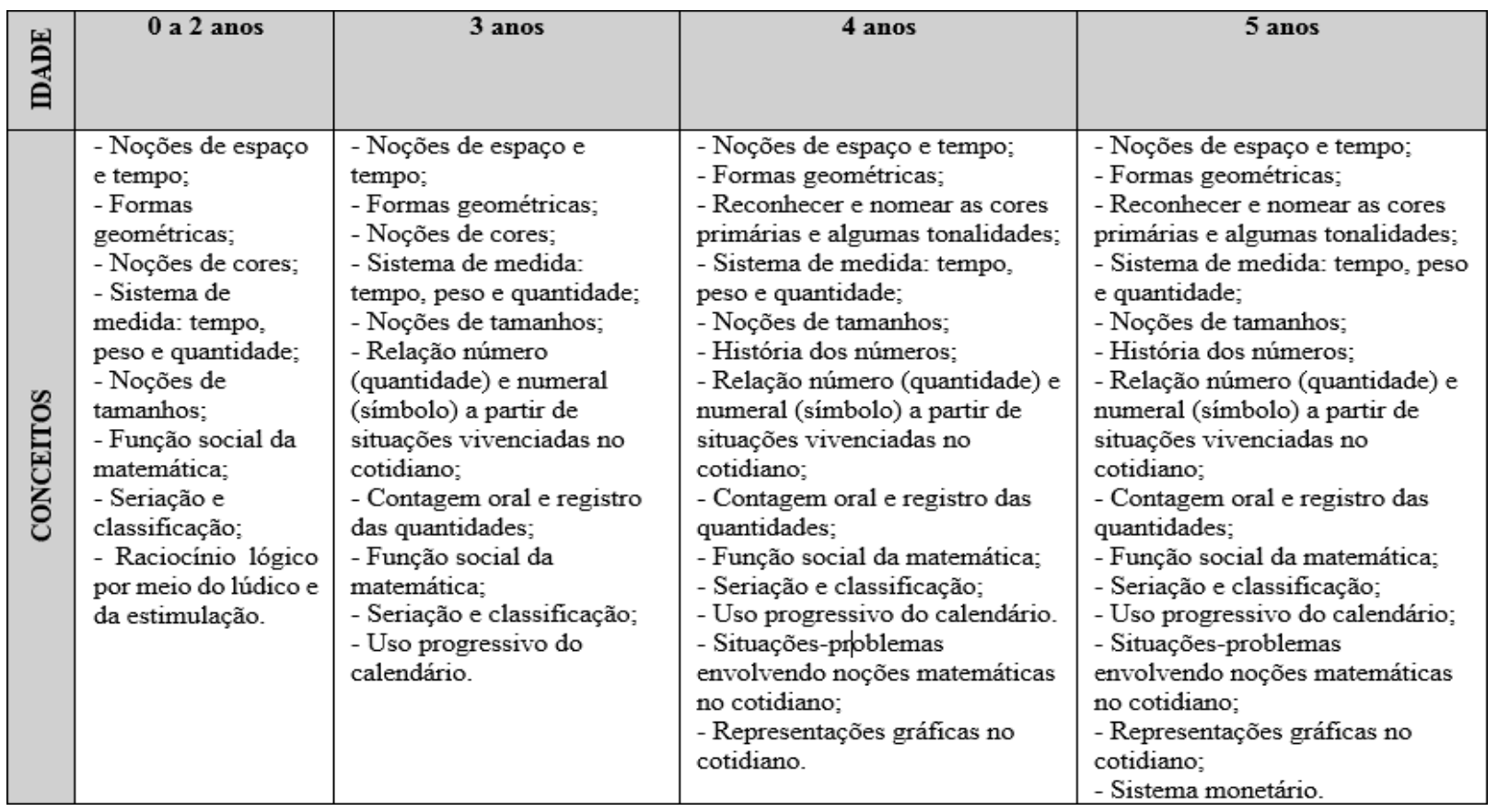

Fonte: Proposta do Município (2012).

Verifica-se no Quadro 1 a separação dos conceitos pela idade das crianças. Para tanto, indica a pedagogia de projetos, que não é condizente com a Teoria Histórico-Cultural. Tal método se oficializa, uma vez que não há indicação de autonomia ao professor para adoção de outra orientação didático-metodológica. Além disso, é questionável que 'cores, tonalidades e uso do calendário' sejam considerados como conceitos matemáticos. Essa relação de conceitos também traz características do construtivismo ao elencar como conceito 'seriação e classificação'. Essa perspectiva teórica, de acordo com Kamii (1986) - ao abordar aspectos do trabalho de Piaget, em seu livro 'A Gênese do Número na Criança' - diz que o número é a síntese entre a seriação e 
classificação. Por sua vez, o ensino desenvolvimental (DAVÍDOV, 1988) concebe o conceito teórico de número como relação entre grandezas, da qual emerge qualquer singularidade numérica (natural, racional, irracional, inteiro e real).

Observa-se, no Quadro 1, a não referência às grandezas de capacidade, comprimento e área. Tais conceitos, na proposição davydoviana, são essenciais para as relações iniciais de introdução da criança no processo formação do pensamento conceitual de número. Davídov (1988) entende que a base inicial de todo conceito matemático, como conteúdo teórico, é ideia de grandeza. Esta propicia o estabelecimento de relação, comparação/medição, desde que de mesma natureza (comprimento com comprimento, área com área, volume com volume, massa com massa, discreta com discreta). No presente estudo, pressuposto é de que, aos 5 anos, é possível que tal relação seja a referência para a introdução do conceito de número real como propõe Davýdov (1982). No entanto, não é essa a intenção da Proposta do Município em estudo (2012, p. 47), que evidencia o teor empírico de número natural. Isso se explicita em indicações como: "Relação número (quantidade) e numeral (símbolo)", "Contagem oral e registro das quantidades" e "Seriação e Classificação". Tal indicação, segundo Rosa (2012), leva a criança a desenvolver o hábito apenas de observar a aparência externa de objetos discretos e associar à quantidade e seu respectivo símbolo numérico. Não estabelece, pois, relações e mediações que suscitem abstrações a serem reduzidas ao pensamento conceitual concreto. Em vez disso, o conceito está dado nos objetos em si, captado pelos órgãos dos sentidos, basicamente, a visão.

Outra evidência da Proposta do Município é o teor pragmático e utilitarista, ao indicar: "partir de situações vivenciadas no cotidiano"; "Contagem oral e registro das quantidades"; "Função social da matemática"; "Uso progressivo do calendário"; "Situações problemas envolvendo noções matemáticas no cotidiano" (MUNICÍPIO X, 2012, p. 47).

Segundo Davídov (1988), a tarefa da escola, no ensino fundamental - em que a atividade principal é o estudo - é promover o desenvolvimento do pensamento teórico matemático dos estudantes, por meio da apropriação consubstanciada de número como relação entre grandezas. Sendo assim, é pertinente que ainda na atividade principal precedente - o jogo na Educação Infantil - surja nos estudantes a necessidade para tal. Isso pressupõe o envolvimento deles em situações que apresente as noções conceituais com o teor teórico, o que significa a não dicotomia entre a utilidade e o conteúdo das noções matemáticas. Nesse sentido, vale destacar o entendimento de Moura (1996) para quem, em todo contexto escolar, predomina a 'atividade pedagógica'. Esta se desdobra em duas, se tomarmos como referência os sujeitos humanos envolvidos: atividade de ensino, peculiar do professor e atividade de aprendizagem, própria do estudante. A mediação entre ambas ocorre pela 'Atividade Orientadora de Ensino (AOE)', desde que elas contemplem as possibilidades das 
crianças se apropriarem da relação essencial do conceito, bem como do seu movimento histórico e lógico.

Mesmo definindo a Psicologia Histórico-Cultural como base teórica, não é esse entendimento de enfoque para o ensino de Matemática da Proposta em estudo. Por sinal, ela não apresenta situações metodológicas com tal referencial para a apropriação conceitual, por parte das crianças. O que se percebe é a ausência de objetivos de aprendizagem com relação aos conceitos selecionados. Disso, decorre interrogações a respeito do modo operacional da organização do ensino para o desenvolvimento do pensamento conceitual teórico das crianças, por exemplo, aqueles inicialmente relacionados, no documento, 'noções de tempo e espaço'. Kalmykova (1991) adverte que a percepção de tempo e espaço, para criança, permanece por um longo tempo na sua forma primitiva, também conhecida como "imagens visuais". Nesse período, a criança confunde sonhos com a vida real e imagina intensas fantasias que, para ela, substituem a realidade. Para que a criança passe desse estágio para outro mais desenvolvido é necessário o contato cultural, que permite a percepção do mundo em sua volta.

Segundo Vygotsky (1994), a ordenação temporal permite a distinção entre tempos linear e cíclico, que leva ao entendimento das ações do homem em um contexto histórico. Do mesmo modo, desenvolverá na criança a noção de duração temporal, como sendo curta, média e longa, que possibilitam a precisão temporal e a relação de diferentes acontecimentos ocorridos historicamente.

Tratando-se da noção do conceito de espaço, Rosa (2012) indica que - na proposição davydoviana - há uma inter-relação com a noção de posição e localização dos corpos. Em outros termos, as tarefas propostas às crianças evidenciam as seguintes relações com teor afirmativo ou negativo (estão ou não estão): em cima de/em baixo de, em frente/ao lado de/atrás, perto/longe, acima/abaixo, à esquerda/à direita e 'fica entre'. Por decorrência, a criança aprende o modo humano de estar no espaço, tendo como referência outros indivíduos humanos, objetos, locais e seres. Ainda, trata-se de uma condição para a apropriação dos conceitos da geometria que, segundo Aleksandrov (1976), estuda as relações entre os corpos geométricos e as figuras, a partir do ponto de vista da grandeza e da posição. Um corpo geométrico é real do ponto de vista de sua forma espacial (inclusive das dimensões), mas sem as propriedades, tais como densidade, cor ou peso. Uma figura geométrica é abstraída de extensão espacial; assim, uma superfície só tem duas dimensões; uma linha, apenas uma e um ponto, nenhuma. $\mathrm{O}$ alto nível de abstração é que distingue a geometria das outras ciências que também estudam as formas espaciais e suas relações.

Um dos objetivos da Geometria na Educação Infantil é desenvolver o pensamento geométrico. Segundo Smole et al (2003), explorar o ensino da Geometria na Educação Infantil não deve restringir-se a tarefas de nomear figuras, mas voltar-se para o desenvolvimento do pensamento 
espacial. Além disso, para pensar Geometria, é necessário contemplar: "1. A organização do esquema corporal; 2. A orientação e percepção espacial; 3. Desenvolvimento de noções geométricas propriamente ditas" (SMOLE et al, 2003, p. 17). Os dois primeiros favorecem orientação e movimentação no espaço, lateralidade, evolução do esquema corporal. $O$ último possibilita perceber propriedades simples (diferenças e tamanhos) nos objetos.

Na proposição davydoviana, as tarefas que trazem como referência as formas geométricas favorecem à criança o desenvolvimento do raciocínio lógico, amplia a noção de número e de medidas. Esse modo de organização de ensino permite a análise e compreensão do espaço físico e muitas situações do mundo à sua volta. (ROSA, 2012).

A proposta em estudo indica outro procedimento metodológico: a "relação de número (quantidade) e numeral (símbolo) a partir de situações vivenciadas pelo cotidiano". Tal orientação permite a afirmação de sua incoerência com a teoria Histórico-Cultural, ao expressar o entendimento de número como a 'relação entre quantidade e símbolo'. Essa incongruência se configura ao se recorrer à afirmação de Vigotski (2001) de que o número, mesmo o natural, extrapola a ideia de contagem, pois se insere em um sistema de conceito em que se atrelam as várias operações matemáticas. Mesmo que se trate de Educação Infantil, ao associar o ensino do conceito à vida cotidiana como uma tentativa de seguir os fundamentos da teoria Histórico-Cultural, corre-se o risco de uma consequência voltada ao desenvolvimento do pensamento empírico. Com isso, não se quer dizer que o ensino desenvolvimental descarta a função didática das situações vividas informalmente pelas crianças. Pelo contrário, elas são referências para elaboração de tarefas desencadeadoras de problematizações, que colocam os estudantes em atitude investigativa na busca da relação essencial que fundamenta um conceito matemático e suas interconexões no âmbito do sistema conceitual. Mas, uma pergunta se apresenta: é possível e é função, na educação infantil, o desenvolvimento do pensamento teórico referente aos conceitos matemáticos? A questão parece-nos que tem um prenúncio de resposta por meio de outras perguntas: se, atualmente, as orientações oficiais - por exemplo, a proposta em estudo - nomeiam conceitos matemáticos a serem ensinados na pré-escola, por que devem ser tratados com teor empírico? Então, o conteúdo empírico dos conceitos apresenta-se, às crianças, como algo natural e dado sem dificuldade alguma para elas, ou seja, os conceitos em sua base empírica não precisam ser ensinados e as crianças os recebem do meio sem o mínimo esforço?

No momento de transição entre a Pré-escola e o Ensino Fundamental, torna-se relevante a contribuição de Davydov (1982), pois concebe a escola, a partir no ensino fundamental, como lugar de aprender o novo, com método novo. O ensino escolar deve proporcionar às crianças a apropriação dos conceitos científicos, que desenvolve o pensamento teórico e as capacidades para o 
domínio independente dos conceitos. Ao se colocar os teores de jogo e teórico nas tarefas - que levam à solução do problema das situações desencadeadoras da aprendizagem - as crianças, assim como no ensino de base empírica, também se confrontam com dificuldades, porém, a vantagem é que a sua superação ocorre em nível teórico.

É nesse modo de organização do ensino de matemática, que se vislumbra as possibilidades de - no período de transição entre a pré-escola e ensino fundamental - a criança em atividade do jogo sinta a necessidade da atividade de estudo. Sendo assim, torna-se de certo modo infrutífero o debate, corrente nos meios educativos, de qual o papel da educação infantil, polarizado entre preparar ou não para a escola formal.

\section{Considerações finais}

A teoria Histórico-Cultural concebe a criança como um ser social que estabelece relação com o mundo, mediada por signos e palavras, a fim de se apropriar do modo humano de ser e, por consequência, satisfazer suas necessidades físicas, materiais, espirituais e culturais. Em outras palavras, é um ser em atividade que medeia a relação dela com a realidade externa. Por isso, em momentos distintos do seu processo de desenvolvimento, há uma atividade que indica as suas possibilidades e o lugar que ela ocupa nas relações sociais, denominada de 'atividade principal' (jogo, estudo e trabalho). O surgimento de novas necessidades indicadoras das possibilidades futuras da criança é o sintoma da passagem para outro nível do processo de formação, uma nova atividade principal, que complexifica a sua relação com a realidade. Na idade pré-escolar, o processo de desenvolvimento é marcado pela atividade do jogo, o que requer atenção ao seu conceito em qualquer orientação de organização do ensino de Matemática que assume como seu fundamento a Teoria Histórico-Cultural. Esse modo de organização do ensino de matemática tem como premissa de que todas tarefas propostas às crianças têm teor de jogo, para que desenvolvam a imaginação, a criatividade e a investigação. Isso requer a não tricotomia ensino/aprendizagem/desenvolvimento.

No entanto, o modo de organização do ensino na Educação Infantil, proposto pelo referido município, sugere e enfatiza uma orientação didática não pertinente à teoria Histórico-Cultural. Suas indicações didáticas apresentam tendência ao construtivismo, à pedagogia de projetos. Enfatiza a adoção de situações do cotidiano das crianças como referência para aprendizagem do conceito de contagem, que se constitui o fundamento do conceito de número. Não traduz, pois, a própria base teórica anunciada, Histórico-Cultural, que traz como conceito fundamental e introdutório a ideia de relação entre grandezas. Sendo assim, a proposta da rede municipal estimula 
a formação do pensamento empírico e não proporciona a base para o desenvolvimento do pensamento teórico.

\section{Referências}

ALEKSANDROV, A. D. Visión General de la Matemática. In:_. La Matemática: su contenido, métodos y significado. $1^{\text {a }}$ ed. Madrid: Alianza Universidade, 1976. p.17-91.

ARAÚJO, E. S. Matemática e infância no "Referencial Curricular Nacional para a Educação Infantil": um olhar a partir da teoria histórico-cultural. ZETETIKÉ - FE - UNICAMP, Campinas, SP, v. 18, n. 33 - jan/jun - 2010.

Princípios e práticas da perspectiva histórico-cultural para o ensino de matemática na infância. XIV CIAEM-IACME, Chiapas, México, 2015. Disponível em: <http://xiv.ciaemredumate.org/index.php/ xiv_ciaem/xiv_ciaem/paper/viewFile/1075/439> Acesso em: 10 maio de 2016.

BRASIL. Diretrizes Curriculares Nacionais da Educação Básica. Brasília: MEC, SEB, DICEI, 2013.

DAVÝDOV, V. V. Tipos de generalización en la enseñanza. 3 ed. Habana: Pueblo y Educación, 1982.

DAVÍDOV, V. V. La enseñanza escolar y el desarrollo psíquico. Moscú: Progreso, 1988.

Uma nova abordagem para a interpretação da estrutura e do conteúdo da atividade. In:

HEDEGARD, M; JUUL, J. U. Activity theory and social practice: cultural-historical approaches. Aarhus (Dinamarca), Aarthus University Press, 1999.

GRANDO, R. C. O conhecimento matemático e o uso de jogos na sala de aula. 2000. 239f. Tese (Doutorado em Educação). Universidade Estadual de Campinas - UNICAMP. Campinas, 2000.

KALMYKOVA, Z. I. Pressupostos Psicológicos para uma melhor aprendizagem da resolução de problemas aritméticos. In: LÚRIA, LEONTIEV, VYGOTSKY et al. Pedagogia e Psicologia II. Lisboa: Estampa, 1991.

KAMII, C. A criança e o número. Campinas, SP: Papirus, 1986.

LEONTIEV, A. O desenvolvimento do psiquismo. Lisboa: Livros Horizonte, 1978.

MOURA, M. O.; LANNER de MOURA, A. R. Matemática na infância. In: MIGUÉIS, Marlene Rocha; AZEVEDO, Maria da Graça (Org.). Educação Matemática na infância: abordagens e desafios. Vila Nova de Gaia: Gailivro, 2007.

. LANNER de MOURA, A. R. Matemática na educação infantil: conhecer, (re)criar um modo de lidar com as dimensões do mundo. São Paulo: Diadema/SECEL, 1998.

MOURA, M. O. A atividade pedagógica na teoria Histórico-Cultural. Brasília: Líber livro, 2010.

A atividade de ensino como unidade formadora. In: BOLEMA, vol. 12. Rio Claro, UNESP, 1996.

. A dimensão da alfabetização na educação matemática infantil. KISHIMOTO, T. M.; OLIVEIRA-FORMOSINHO, J. (org.). Em busca da pedagogia da infância: pertencer e participar. Porto Alegre: Penso, 2013. 
MOURA, M. O.; ARAÚJO, E. S.; MORETTI, V. D.; PANOSSIAN, M. L.; RIBEIRO, F. D. Atividade orientadora de ensino: unidade entre ensino e aprendizagem. Rev. Diálogo Educ., Curitiba, v. 10, n. 29, p. 205-229, jan./abr. 2010.

ROSA, J. E. Proposições de Davydov para o ensino de matemática no primeiro ano escolar: inter-relações dos sistemas de significações numéricas. 212. 244f. Tese (Programa de Pósgraduação em Educação) - Universidade Federal do Paraná, Curitiba, 2012.

SMOLE, K. S.; DINIZ, M. I.; CÂNDIDO, P. Figuras e formas. Porto Alegre: Artmed, 2003. VIGOTSKI, L. S. A construção do pensamento e da linguagem. São Paulo: Martins Fontes, 2001. 